\title{
ANALYSIS OF MAIN REQUIREMENTS FOR ELECTRONIC DOCUMENT MANAGEMENT SYSTEMS
}

\author{
Nazila Ali Ragimova ${ }^{1}$, Vugar Hajimahmud Abdullayev ${ }^{2}$, Vasila Soltanaga Abbasova ${ }^{3}$ \\ ${ }^{1}$ Department “Computer Engineering”, Azerbaijan State University of Oil and Industry, Baku, Azerbaijan \\ ${ }^{2}$ Department "Computer Engineering", Azerbaijan State University of Oil and Industry, Baku, Azerbaijan \\ abdulvugar@mail.ru \\ ORCID: http://orcid.org/0000-0002-3348-2267 \\ ${ }^{3}$ Department "Computer Engineering”, Azerbaijan State University of Oil and Industry, Baku, Azerbaijan, AZ1010
}

ARTICLE INFO

Article history:

Received date 09.01.2020

Accepted date 23.01.2020

Published date 31.01 .2020

Section:

System Administration

DO I

$10.21303 / 2313-8416.2020 .001148$

\section{KEYWORDS}

paper document

electronic document

document management

automation of document management

electronic document management system

\section{ABSTRACT}

This article discusses the document management of the enterprise, automation of "mechanical" document management, as well as advantages and disadvantages of electronic document management systems. Thus, the advantages of electronic document management systems include the following: saving time, more adequate use of physical space and technology. As well as increasing the transparency of the internal work of the enterprise, more flexibility with regard to the physical location of employees, improving the security of information and documents, reducing the cost of printing, postage stamps, envelopes and forwarding. In addition, the study transmitted the value of the document and its place in the company's office. The requirements of customers to electronic document management systems are also affected. In conclusion, we have reviewed the requirements for electronic document management systems and identified the main requirements for such systems. The main requirement of customers is financial costs. It is on them that depends on which modules of the electronic document management system will be preliminary.

(C) The Author(s) 2020. This is an open access article under the CC BY license http://creativecommons.org/licenses/by/4.0).

\section{Introduction}

In enterprises, information can be represented in two ways as structured and unstructured. In the first case, the information is presented as a database, and in the second case, the information is presented as documents. [1]

Documents that are able to keep trade secrets sometimes occupy a special place in all corporations. A document is information stored in a tangible medium as text. And electronic documents are an electronic version of the document stored in digital form, which allows reducing time and costs over "mechanical" document circulation [2]. Documents in enterprises mean certificates, statements, contracts, protocols, acts, etc. According to the presentation form, three types of documents are paper, micrograph and electronic.

\section{Literary review}

A system that is aimed at creating, receiving, transmitting and archiving documents, as well as monitoring the execution and ensuring the protection of documents throughout the life cycle, is called document management [4].

The goal of any enterprise is to make the company's document management as efficient, reliable, as fast as possible, but at the same time less time-consuming and expensive [5].

The main driving force of the enterprise to automate the document management processes is to identify problems, which in the form of a tree of problems are shown in Fig. 1 [6].

Based on the received problem tree, a target tree was built (Fig. 2), which is aimed at solving these problems [6]. 


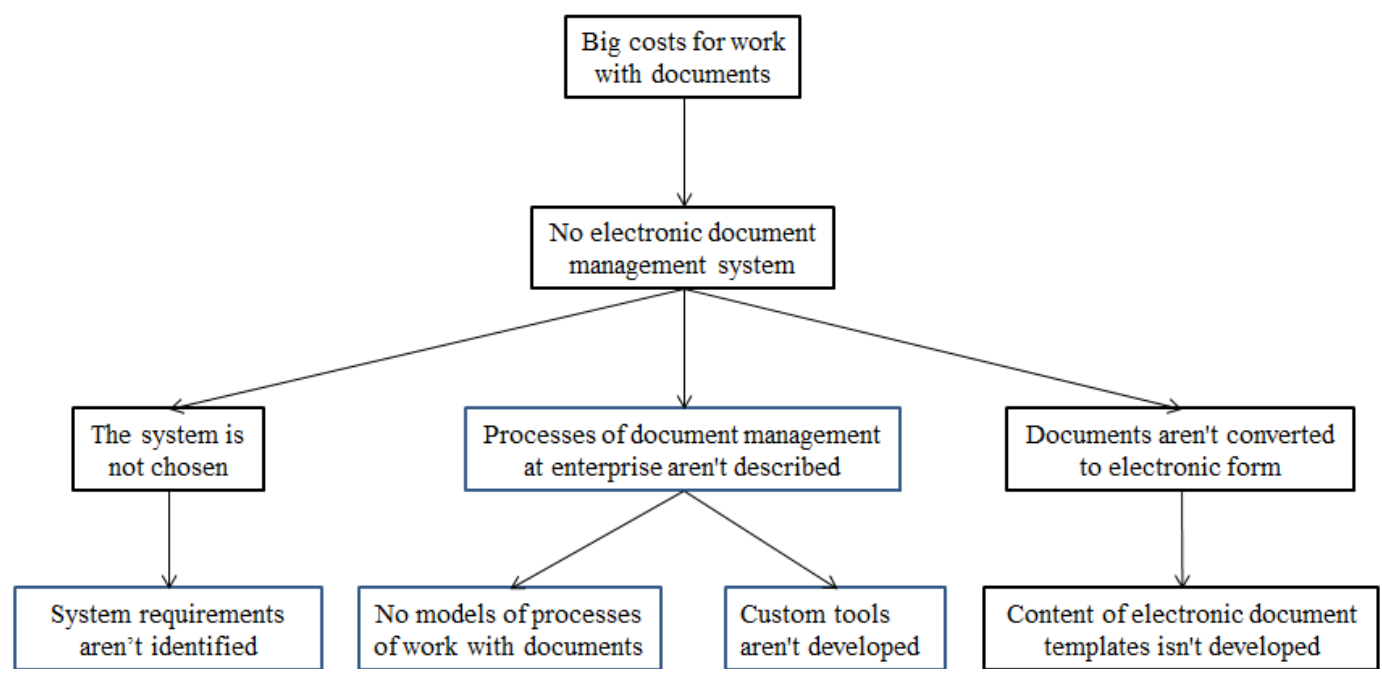

Fig. 1. Tree of problems

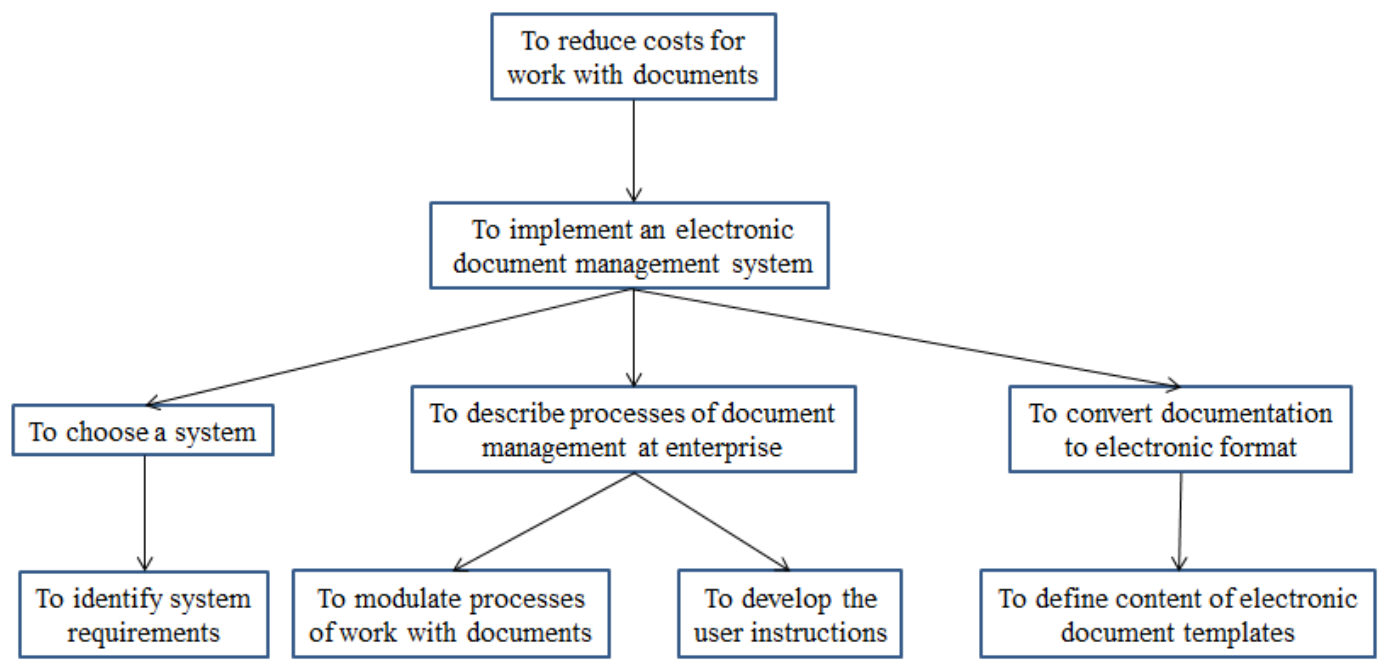

Fig. 2. Tree of targets

\section{Aim and objectives of research}

The aim of research is to analyze the basic requirements for electronic document management systems.

To achieve the aim, the following objectives are set:

1. Determine the benefits of electronic document management systems;

2. Analysis of modern requirements for electronic document management systems.

\section{Electronic Document Management System}

Electronic Document Management System (EDMs) is a system that allows organizing, managing and automating work with electronic documents during their entire life cycle, as well as processes of interaction between employees. [7]

In general, the electronic document management system of the organization can be considered as a central system that coordinates the document management subsystems, which, in its own turn, works as the core of the company's production operations system. The EDMs can be viewed as a centralized system in that it stores all documents in a single repository. The main object of automation in these systems is paper [8].

The benefits of EDMs include:

- Save time: Employees reduce time to search for paper documents.

- More adequate use of physical space and technology. It is possible to reduce the cost of physically storing documents with documents stored electronically. 
- Increase the transparency of the internal operation of the enterprise. The EDMs allows managers to monitor the current status of documents, as well as to obtain more detailed information about them (who created it, who had access to it, and who edited it and other information).

- More flexibility regarding the physical location of employees. Because documents are stored electronically, employees can work remotely with them.

- Improve security of information and documents. Because of the central database, documents are constantly backed up, thus eliminating the possibility of irretrievable document loss.

- Lower printing, postage stamps, envelopes and shipping costs. It is possible to reduce the cost of transferring documents because they exist and are transmitted internally [9].

In addition to these advantages, these systems have the following main disadvantages:

- System implementation and training costs;

- EDMs allows document circulation within one corporation, but not with other enterprises [10].

In order to realize all the advantages of electronic document management systems, they are subject to the requirements described below.

\section{1. Main requirements for EDMs}

The main requirements for electronic document management systems are compliance with the availability, integrity and confidentiality of documents [11].

EDMs should provide access to documents for both five and thousands of users of the system. However, the performance and reliability of the system should not be reduced.

Several employees of the enterprise are able to work on documents. When working with documents, the electronic document management system must ensure document integrity. And protect against unauthorized access to documents. The EDMs must also be equipped to support remote users.

The EDMs shall be presented as a distributed information system consisting of different modules. At the same time, the EDMs can be a module of the corporate information system. To integrate with other systems, it must have open interfaces [12].

Documents have different life cycles, in which after some time they begin to lose power and are then archived. As a result, the EDMs must contain document archiving tools. There are currently two models of archives:

- Dynamic archives, which are organized on magnetic, optical and magnetic-optical media;

- Static archives, here microfilm is used as storage medium;

- Hybrid archives. Many companies prefer to use a combination of the first spirit of archives [13].

In addition to these requirements, electronic document management systems have a special requirement to ensure data confidentiality. For this purpose, two types of authorizations are used in electronic workflow systems:

- Privilege is a system-oriented authority that extends to the entire system. For example, creating or deleting users, viewing documents of other users when they have problems. These powers are owned by system administrators;

- Permissions are object-oriented authorities that apply to the corresponding object. Permissions determine what users can do over an object (folder, document, and other system items). Different system objects can have different permissions, for example, documents have the following permissions: to see the document itself; to see its contents; to change it; modify its attribute values, delete it, and grant permissions to other users.

Reliable hardware is required to ensure stable operation of the electronic document management system. For example, to maintain a large number of users' on-line access to documents, higher-speed hard drives will need to be implemented, and multiple servers will need to be connected to keep the EDMs running.

It is also a separate EDMs requirement to have a simpler, more flexible and reliable search tool. There are two methods of searching documents in modern electronic document management systems.

The first method of finding documents is to find a document by attributes. As attribute it is understood data of the document (the author, creation time, time of the last change by whom the last time was changed also other information). 
And the second method is to search for a given phrase inside the text of the document. Here it is possible to search for the exact matching of phrases or find one of the phrase words inside the text of the document. It is also desirable to be able to search electronic document management systems by synonyms, antonyms, by similarity of writing, similarity of phrase pronunciation and by other features of phrases.

The EDMs must contain powerful software tools for implementing business processes and must also be capable of providing a graphical user interface.

The requirements of electronic document management systems can also include justifications for investments made in it. Since the corporation spends a lot of money to implement EDMs, it must justify itself. EDMs, like other information systems, pays off in the long term. Enterprises are also trying to save on costs when implementing EDMs.

\section{Research results}

To reduce costs, customers can only take the necessary functionality of electronic document management systems. Like other information systems, customers have their own requirements. Among all the requirements are the most significant:

- Make documents available to all employees of the corporation;

- Ensure document integrity throughout the lifecycle;

- Ensure confidentiality of documents, including ensuring the protection of documents from unauthorized access;

- Reliable archiving tools available;

- Ensure system modularity;

- Reliable hardware;

- A powerful document search tool;

- Availability of tools for implementing business processes and graphical user interface;

- Justifications of investments.

\section{Conclusions}

The following findings emerged from the research:

1. Advantages of electronic document management systems include time savings, more adequate use of physical space and equipment, increased transparency of internal work of the enterprise, more flexibility in physical location of employees, improvement of security of information and documents, reduction of costs for printing, postage stamps, envelopes and forwarding.

2. The main requirement of customers is financial costs. They depend what type of EDMs modules will be acquired.

\section{References}

[1] Kamennova, M. (1995). Upravlenie elektronnymi dokumentami: tekhnologii i resheniia. Otkrytye sistemy, 4.

[2] Ot avtomatizacii ofisa do upravleniia proizvodstvom (2000). Open Systems, 8.

[3] Kodd, E. F. (1995). Reliacionnaia model dannykh dlia bolshikh sovmestno ispolzuemykh bankov dannykh. SUBD, 1, $145-160$.

[4] Perkinson, R. S. (2005). Analiz dannykh: Kliuch k proektirovaniiu baz dannykh. Kyiv: Dialektika, 329.

[5] Proektirovanie i razrabotka sistem avtomatizacii predpriiatii.

[6] Zolotova, S. (2000). Avtomatizaciia i statistika. Finansovaia gazeta, 35.

[7] Zyrianov, M. (2003). K oruzhiiu. Moschnoe sredstvo v borbe za vyzhivanie. ComputerWorld, 40.

[8] Database Unleashed. Indianapolis (1996). SAMS Publishing.

[9] Datem, C .J. (2004). An Introduction to Database System» Vol. 1. Mass.: Addision - Wesley Publishing Company.

[10] Masalovich, A. (2003). Bogatym byt luchshe ... ITWeek, 40 (214). Available at: https://www.itweek.ru/idea/article/detail. php?ID $=52383$

[11] Bogatova, T. (1999). Kompanii "Parus" i BIG vooruzhaiut finansistov. ITWeek, 40 (214). Available at: https://www.itweek.ru/ idea/article/detail.php?ID=52387

[12] Pakhomov, E. V. (2012). Analiz sistem elektronnogo dokumentooborota v organakh municipalnogo upravleniia. Izvestiia iuzhnogo federalnogo universiteta. Tekhnicheskie nauki, 188-194.

[13] Efremova, L. I (2019). Vybor sistemy elektronnogo dokumentooborota dlia predpriiatiia. Vestnik Volzhskogo universiteta im. V. N. Tatischeva, 2 (1), 23-31. 